\title{
Synopsis of the Argentinian scarab genus Pseudogeniates Ohaus (Coleoptera, Scarabaeidae, Rutelinae)
}

\author{
Mary Liz Jameson', Federico Ocampo ${ }^{2}$ \\ I Wichita State University, Wichita, Kansas, USA 2 Instituto Argentino de Investigaciones de Zonas Aridas - \\ Instituto de Ciencias Básicas, CCT-CONICET Mendoza, Argentina \\ Corresponding author: Mary Liz Jameson (maryliz.jameson@gmail.com)
}

Academic editor: Andrey Frolov | Received 9 August 2012 | Accepted 23 October 2012 | Published 13 November 2012

Citation: Jameson ML, Ocampo F (2012) Synopsis of the Argentinian scarab genus Pseudogeniates Ohaus (Coleoptera, Scarabaeidae, Rutelinae). ZooKeys 241: 33-53. doi: 10.3897/zookeys.241.3802

\begin{abstract}
The scarab beetle genus Pseudogeniates Ohaus (Scarabaeidae: Rutelinae: Rutelini) is endemic to Argentina. The genus includes three species: P. cordobaensis Soula, P. intermedius Ohaus, and P. richterianus Ohaus. We characterize the genus, provide a key to species, redescribe and diagnose each species, provide spatial and temporal distributions, and discuss distributions of the species in relation to eco-regions and areas of endemism in Argentina.

\section{Resumen}

El género de escarabajo Pseudogeniates Ohaus (Scarabaeidae: Rutelinae: Rutelini) es endémico de Argentina. El género incluye tres especies: $P$. cordobaensis Soula, $P$. intermedius Ohaus, y $P$. richterianus Ohaus. En este trabajo caracterizamos el género, proveemos una clave para las especies, redescribimos y proveemos diagnosis para cada una de ellas y datos de su distribución temporal y espacial y discutimos aspectos de las distribuciónes de las especies en relación de las regiones eco-regiones y áreas de endemismo en Argentina.
\end{abstract}

\section{Keywords}

Endemic, Pampa, Monte, Chaco, intraspecific variation

\section{Introduction}

The leaf chafer genus Pseudogeniates Ohaus (Rutelinae: Rutelini) (Figs 1-3) is endemic to Argentina. Species in the genus are associated with arid habitats in the Pampa, Espinal, Monte, and Chaco eco-regions (Fig. 22) (eco-regions as in Ponce et al. 2002).

Copyright M.L.Jameson, F. Ocampo. This is an open access article distributed under the terms of the Creative Commons Attribution License 3.0 (CC-BY), which permits unrestricted use, distribution, and reproduction in any medium, provided the original author and source are credited. 
Pseudogeniates species are moderate-sized $(12-19 \mathrm{~mm})$, elongate-oval, brown scarabs with striate elytra (Figs 1-3). In many respects, species in the genus are similar in overall gestalt to species in the genus Geniates Ohaus (Rutelinae: Geniatini) or drabcolored species in the genus Anomala Samouelle (Rutelinae: Anomalini). Actually, however, form of the labrum, elytra, protibia and tarsomeres, and position of the terminal spiracle, place the genus in the tribe Rutelini (Rutelinae) (see "Classification"). Female gender bias in the most wide-spread species and the fact that specimens are rarely encountered in collections have both contributed to the difficulty in circumscribing species in the genus. Our work revealed a high degree of intraspecific variation that may be due to spatial or temporal isolation of populations. Thus, in addition to rarity and sex bias, circumscription of species is complicated by variation in character states. Heretofore, there has been no comprehensive review of species in the genus. This research provides a synopsis of the three species in the genus and information on the distribution of these poorly studied species.

\section{Taxonomic history}

Ohaus (1910) named the genus Pseudogeniates for one species, P. richterianus Ohaus, and he based the description on female specimens alone. He puzzled over classification of the genus, discussing its affinities with the ruteline tribes Geniatini and Anoplognathini. Both of these tribes are orthochilous rutelines, that is, they belong to a broad group of Rutelinae in which the mouthparts (specifically labrum and mentum) project vertically with respect to the head (Ohaus 1918, 1934; Machatschke 1965; Jameson and Hawkins 2005). Based on overall gestalt and proportions of the "hind body", Ohaus (1910) compared P. richterianus with Geniates barbatus Kirby and G. cylindricus Burmeister (both Geniatini from South America). He also compared the genus with Saulostomus weiskei Ohaus and S. felschei Ohaus (both Anoplognathini from Australia) based on the form of the mouthparts. The form of the clypeus and mouthparts were so unusual that when Ohaus first saw specimens, he "believed that the animal was crippled" (Ohaus 1910: 179). After studying two additional female specimens from a different locality, Ohaus realized that these peculiarities were not teratological. Despite lacking male specimens, he described $P$. richterianus, but he declined placing the new genus and species in a ruteline tribe, stating that this would require additional characters from male specimens (Ohaus 1910).

After obtaining additional specimens of Pseudogeniates and making comparisons with other Argentinian fauna, Ohaus (1914) placed the genus in the tribe Rutelini (Rutelinae), a tribe of homalochilous rutelines that is characterized by the labrum that is horizontally produced with respect to the clypeus. He discussed affinities of Pseudogeniates with Homonyx Guerin and Parhomonyx Ohaus, both of which are distributed in southern South America and both members of the subtribe Pelidnotina. Based on both male and female specimens, Ohaus (1914) described a new species, P. intermedius. Ohaus characterized the two species using differences in the form of the clypeus and antennae: 
P. richterianus possessed nine-segmented antennae (thus differing from all other Rutelini) and $P$. intermedius possessed ten-segmented antennae (the hypothesized ancestral state within the Rutelini). The antennal character state in P. richterianus make this species an exception in the key to tribes of Rutelinae (see Jameson 1990, 2005). However, Ohaus did not have a broad enough sampling of specimens of $P$. richterianus to understand the intraspecific variation of this character: antennae are either 9- or 10-segmented in $P$. richterianus. This variation has confounded identification of Pseudogeniates species.

The Genera Insectorum on the Rutelini (Ohaus 1934) languished for more than 20 years before publication. Realizing the great delay, Ohaus (1915) published his concepts of higher taxa and descriptions of genera. He formalized use of the subtribe Pelidnotina (as "Pelidnotinorum") and commented on evolution and affinities of Pseudogeniates, Parhomonyx, and Homonyx. He considered Parhomonyx to be an "intermediate stage" that "led Homonyx to Pseudogeniates" (Ohaus 1915: 258), and that characters of the coloration, clypeus, mouthparts, elytra, hind tibia, and antennae indicated these relationships (or this progression of forms). He thought that these taxa were a good example of how differences in rainfall (dry versus wet; e.g., Ponce et al. 2002) and differences in habitat (forest versus steppe) produced adaptations and changes in morphological characters. He also stated that the Argentinian fauna offered a number of examples of these evolutionary transformations, particularly in scarab beetles.

Nearly 100 years after Ohaus' work on Pseudogeniates, Soula (2009) reviewed the genus based on six specimens in the Ohaus collection (housed at ZMHB), described a new species, $P$. cordobaensis, based on specimens from the type series of $P$. intermedius (which included three males and one female specimen), described the type specimens for each of the species of Pseudogeniates, and commented briefly on the unusual character states of the genus. Soula's species descriptions are not comparative; they do not allow separation and identification of species in the genus; and, because they are based on a limited number of specimens, they do not take into account variation within the species. In addition, Soula (op. cit.) did not provide a key to species and diagnoses. For these reasons, Soula's work is of little utility for identification and understanding of biodiversity of this group.

\section{Definition of taxonomic characters and character examination}

This research is based on 56 specimens from collections including type specimens. About one third of these specimens (19 specimens) were identified in collections; the remaining two thirds were not identified. Out of the 19 specimens that were identified, 9 were incorrectly identified, 4 were correctly identified, and 6 were type specimens. Two specimens were incorrectly identified to genus. Specimens for this research are deposited at the CMNC (Canadian Museum of Nature Collection, Ottawa, Canada), FMNH (Field Museum of Natural History, Chicago, Illinois, USA); IAZA (Instituto Argentino de Investigaciones de Zonas Áridas, Mendoza, Argentina); MACN (Museo Argentino de Ciencias Naturales, Buenos Aires, Argentina); MLJC (Mary Liz Jameson collection, 
Wichita, Kansas, USA); UCCC (Universidad de Concepción, Concepción, Chile); USNM (United States National Collection, Washington, D.C., USA); and ZMHB (Museum für Naturkunde der Humboldt Universitat zu Berlin, Berlin, Germany).

Morphological characters formed the basis of this work. The broadest range of potentially phylogenetically informative morphological characters was used for morphological analyses and comparisons. For measurements, we used an ocular micrometer. Body measurements, puncture density, puncture size, and density of setae are based on the following standards. Body length was measured from the apex of the clypeus to the apex of the pygidium. Body width was measured at the widest width of the elytra. Puncture density was considered 'dense' if punctures were nearly confluent to less than two puncture diameters apart, 'moderately dense' if punctures were from two to six puncture diameters apart, and 'sparse' if punctures were separated by more than six puncture diameters. Puncture size was defined as 'small' if punctures were $0.02 \mathrm{~mm}$ in diameter or smaller; 'moderate' if $0.02-0.07 \mathrm{~mm}$, 'moderately large' if $0.07-0.12 \mathrm{~mm}$, and 'large' if $0.12 \mathrm{~mm}$ or larger. Setae density was defined as 'dense' if the surface was not visible through the setae, 'moderately dense' if the surface was visible but with many setae, and 'sparse' if there were few setae. It should be noted that setae are subject to wear and may be abraded away. Elytral discal striae are defined as the striae located between the elytral suture and the elytral humerus. The interocular width measures the number of transverse eye diameters that span the width on the frons between the eyes. This was measured by placing the ocular micrometer in a position such that it intersects the frons and eyes (dorsal view), focusing on the surface of the frons, and then measuring the width of the frons and width of the eyes without adjusting the focus. Mouthparts, wings, and genitalia were examined and card-mounted beneath the specimen. Some specimens were quite fatty, with internal and external greasy build-up. These specimens were cleaned in acetone prior to dissection.

Characters and specimens were observed with 6-48× magnification and fiber-optic illumination. Digital images of specimens and structures were captured using the Leica Application Suite V3.8. Images were edited in Adobe Photoshop CS2 (background removed, contrast manipulated).

Species are characterized by combinations of characters including the form of the mentum and maxilla, form of the metacoxa, and form of the ventral plate of the male parameres. We use the phylogenetic species concept (Wheeler and Platnick 2000) in this work: "A species is the smallest aggregation of (sexual) populations or (asexual) lineages diagnosable by a unique combination of character states."

Specimen localities were translated into latitude and longitude using GoogleEarth (http://www.google.com/earth/index.html). Maps were generated by entering these data into Microsoft Excel 2008 and uploaded to EarthPoint (http://www.earthpoint.us/ExcelToKml.aspx) and GoogleEarth (Supplementary File: Pseudogeniates Locality Table.xls). These tools allow for interactive mapping and addition of data by subsequent users. Description of Argentinian eco-regions follows Ponce et al. (2002). Argentinian areas of endemism follow Cabrera and Willink (1973) and Szumik et al. (2012). 


\section{Pseudogeniates Ohaus, 1910}

http://species-id.net/wiki/Pseudogeniates

Figs $1-22$

Pseudogeniates Ohaus 1910: 179-180

Type species. P. richterianus Ohaus 1910: 180. By monotypy.

Tribal classification. The genus Pseudogeniates is a member of the tribe Rutelini. In overall appearance, however, species in the genus Pseudogeniates are similar to species in the genera Geniates (Geniatini) and Anomala (Anomalini). Species in the genus Pseudogeniates can be separated from both of these tribes based on the margin of the elytra that lacks an obvious membranous border (membranous border present at the elytral apex in both Geniatini and Anomalini). Additional characters that separate the Rutelini and Geniatini include: the labrum that is horizontally produced with respect to the clypeus in the Rutelini (vertically produced in the Geniatini) and protarsomeres that are subcylindrical and lacking ventral setose pads (dorsoventrally flattened and densely setose ventrally in the Geniatini). Additional characters that separate the Rutelini and Anomalini include: protibia with inner, protibial spur apical in the Rutelini (inner, apical spur subapical in Anomalini) and terminal spiracle positioned in pleural suture in the Rutelini (terminal spiracle not positioned in pleural suture in Anomalini). For a key to tribes of Rutelinae, see Jameson (1990, 2005).

Subtribal classification. Ohaus $(1915,1934)$ placed the genus Pseudogeniates in the tribe Rutelini and subtribe Pelidnotina. Based on morphological data, this subtribe was demonstratively paraphyletic and it was eliminated (Jameson 1998). Soula (2009), without justification or discussion, continued use of this higher-level taxon for the genus. We consider the genus Pseudogeniates to be a member of the tribe Rutelini (without subtribal designation).

Phylogeny. Sister group relationships have not been examined for the genus or for species within the genus.

Diagnosis of adults. Members of the genus Pseudogeniates differ from other genera in the tribe Rutelini by the following combination of characters: feathery fringe of setae on the ventral edge of the elytra present; elytra obviously striate (Figs 1-3); mesosternal peg lacking; claws simple on all legs (not toothed) (Figs 11-13); frontoclypeal suture incomplete (Figs 16-18); clypeal apex broadly reflexed (Figs 16-18); apex of labrum extending beyond clypeal apex, visible from dorsal view (Fig. 18); apex of mandible with one, apical, recurved tooth (Figs 4, 18); maxillary teeth lacking (Fig. 5).

Similar taxa. Species in the genus Pseudogeniates share several characters with Parhomonyx fuscoaeneus Ohaus, a monotypic taxon that is also endemic to southern South America. The following characters are shared: fringe of setae at apex of elytra, mesosternal process lacking, mandible with one external tooth, elytra striate, and claws simple. However, Pseudogeniates differs from Parhomonyx based on the external margin of the mandible that is straight (external margin lobe-like in Parhomonyx), maxillary teeth lacking (maxilla with well developed teeth in Parhomonyx), maxillary palp rod-shaped 


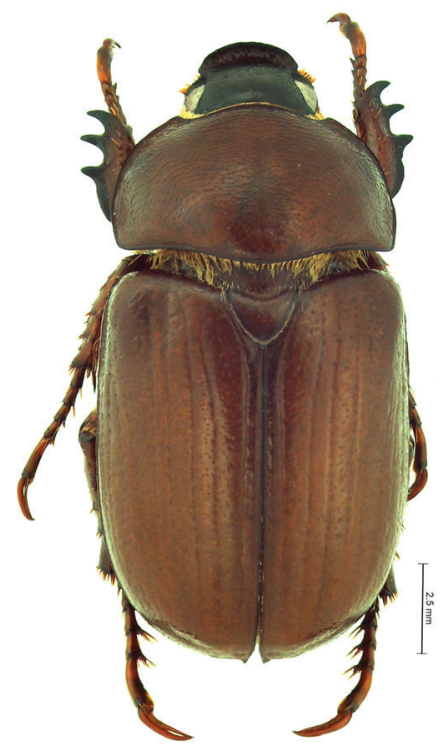

1. P. cordobaensis

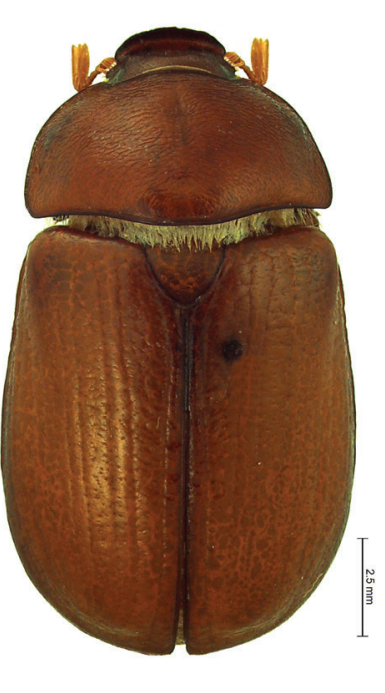

2. P. intermedius

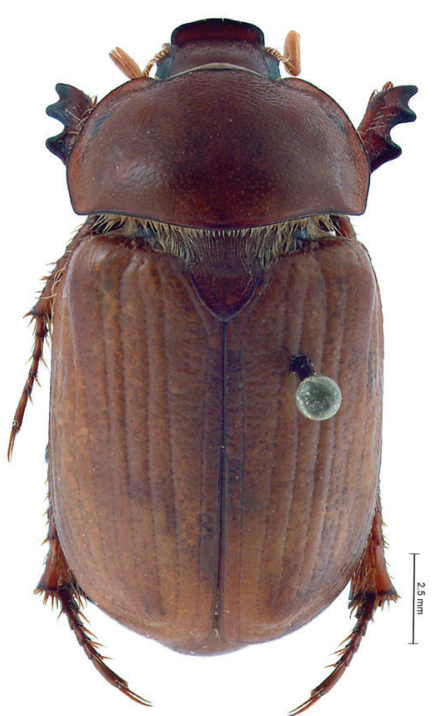

3. P. richterianus

Figures I-3. Dorsal habitus of Pseudogeniates species I P. cordobaensis $\mathbf{2}$ P. intermedius $\mathbf{3}$ P. richterianus

(broadly elliptical in Parhomonyx), and fifth tarsomere on all legs of males and females lacking an internal tooth (with two well developed internal teeth on the fifth mesoand metatarsomeres of males and females of Parhomonyx).

Description of adults. Length from apex of clypeus to apex of pygidium 12.0-19.0 $\mathrm{mm}$; width at mid-elytra $6.0-11.0 \mathrm{~mm}$. Color: Dorsal and ventral surfaces testaceous to castaneous. Form (Figs 1-3): Elongate oval, sides subparallel, pygidium exposed beyond apices of elytra, apex of elytra broadly rounded. Head (Figs 16-18): Disc of frons and clypeus in lateral view nearly flat, clypeus with margins and apex reflexed. Frons and clypeus variably sculptured, punctate and/or rugose. Frontoclypeal suture weakly indicated, incomplete at middle. Eye canthus weakly cariniform. Interocular width 2.9-4.8 transverse eye diameters. Clypeal apex rounded or quadrate, with or without basolateral constriction, lacking bead; frontal view flat, length (at middle) about $1 / 3$ length of frons, disc variably punctate and setose. Mandible (Fig. 4) with 1 apical, acute, recurved tooth; scissorial region with 1 poorly developed tooth; molar region narrow. Labrum projecting beyond clypeus, trapezoidal, apex emarginate or quadrate; apex moderately emarginate medially, surface moderately densely punctate, punctures moderate in size, some setose (setae moderately long and short, rufous). Maxilla (Fig. 5) lacking teeth; galea fused or not, with moderately dense, moderately long setae and with 1 to 2 long, bristle-like seta on disc; terminal segment of palpus with dorsal, longitudinal sulcus from based to sub-apex. Mentum (Figs 8-10) rectangular, trapezoidal, or pentagonal, inner apex produced anteriorly or not, with or without inner shelf. Antenna 9 or 10-segmented with 3-segmented club; club subequal in length to segments 1-7 combined or slightly longer than segments 1-7 combined. Pronotum: 
Widest at middle, apical angles obtuse, basal angles obtuse. Dorsal surface punctate, rugopunctate, or imbricate, with or without median line. Bead complete anteriorly, laterally, and basally. Margin sparsely setose (setae short, rufous). Scutellum: Parabolic, wider than long; base declivous at elytral base. Wing: Dense, thick setae present anterior to RA3+4 to apex; ScA with dense, thick setae near fold, lacking precostal pegs; $\mathrm{AA} 1+2$ shorter than AA3+4 (Fig. 7). Mesepimeron: Apex entirely hidden by base of elytra in dorsal and lateral views. Elytra: Variably sculptured with longitudinal, punctate striae; punctures variable. Sutural stria sulcate, impressed from base of scutellum to apex. Epipleuron from base to mid-metacoxa with shelf and associated setae; epipleuron from mid-metacoxa to apex beaded and with associated setae. Apex of elytra weakly rounded; sutural apex spiniform, rounded, or square. Elytral sutural length about 6.5 times length of scutellum. Propygidium: Hidden beneath elytra. Pygidium: Semitriangular, about twice as wide as long at middle; variably sculptured, punctate, shagreened, or weakly rugose. Margins beaded. Apex rounded. Apical bead with moderately long to long setae; setae tawny to rufous or testaceous. Venter: Prosternal keel triangular; apex projecting anteroventrally at about $35^{\circ}$ with respect to ventral plane; apex produced to level of protrochanter, blunt; surface flat (lacking protuberance). Mesometasternal keel lacking. Sternites 1-4 subequal in length in male and female, sternites 5-6 about twice length of sternite 4. In lateral view, male sternites flat, female sternites weakly convex. Last sternite with apex quadrate in male, posteriorly rounded in female. Legs: Protibia (male and female) with width at base $1 / 3^{\text {rd }}$ to $1 / 4^{\text {th }}$ greater than width at apex (Figs 11-13), inner base with weak Protibial notch, with 3 external teeth in apical half ( 2 apical teeth removed from basal tooth external teeth or not); spur present, subapical. Modified foreclaw of male (Fig. 11) about 3 times width of unmodified claw, not toothed, inner apical tooth present at apex, small. Foreclaws of female simple, internal claw slightly wider than outer claw. Unguitractor plate laterally flattened, exposed beyond tarsomere 5; apex with 0-1 moderately long setae. Mesotibia with sides subparallel, apex weakly divergent; external edge with 2 carinae; inner apex with 2 spurs; apex with 10-20 spinulae. Meso- and metatarsomere 4 apicomedially with 4 medial spinulae (male) or 2 medial spinulae and 1 seta-like long spinule laterad of each medial spinula (female). Meso- and metatarsal claws of male and female simple, internal claw slightly wider than outer claw. Metarsomere 1 moderately divergent at middle and apex (male and female). Metatrochanter with apex weakly produced beyond posterior border of femur. Metacoxal corner (female) rounded or square. Metatibia (Figs 14-15) with sides subparallel, divergent towards apex; external edge with 1-2 carinae; inner apex with 2 spurs; inner apex with 25-40 short, stout spinulae. Spiculum gastrale: Y-shaped, lacking associated sclerites (Fig. 6). Parameres and phallobase: Plates fused dorsally/ventrally (not laterally). Dorsal plate symmetrical, apex rounded and with or without two apical, rounded teeth (Figs 19-21); not diagnostic for species. Ventral plate elongate (as long as dorsal plate or $1 / 2$ length of dorsal plate), apex acute, quadrate, or rounded; diagnostic, species specific (Figs 19-21). Parameres slightly longer than phallobase. Female Genitalia: Gonocoxites subquadrate with sparse setae; not diagnostic for species. 


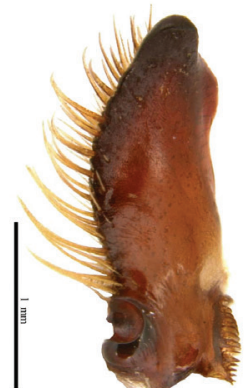

4. P. richterianus

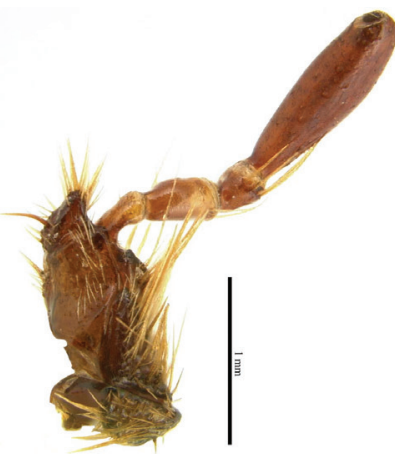

5. P. cordobaensis

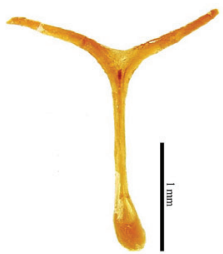

6. P. cordobaensis

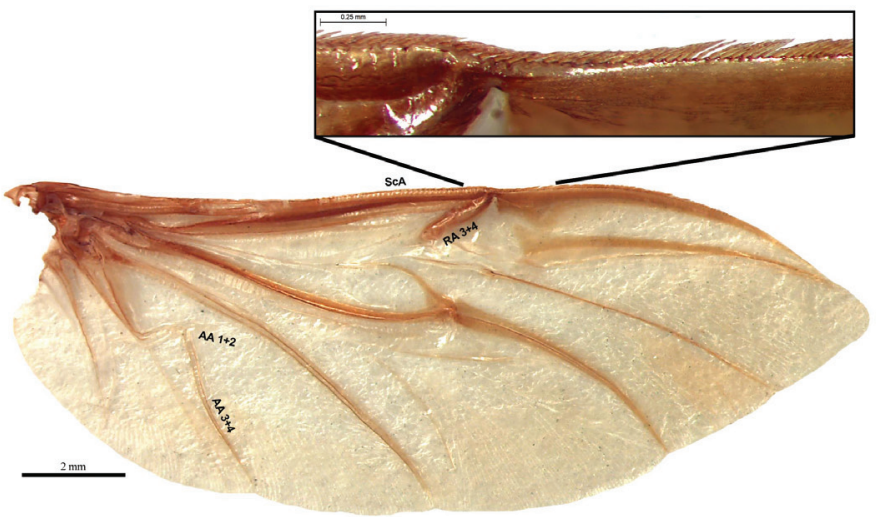

7. P. richterianus

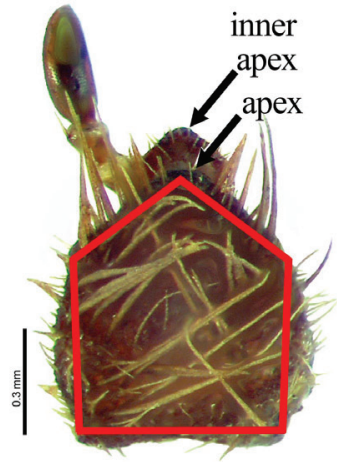

8. P. cordobaensis

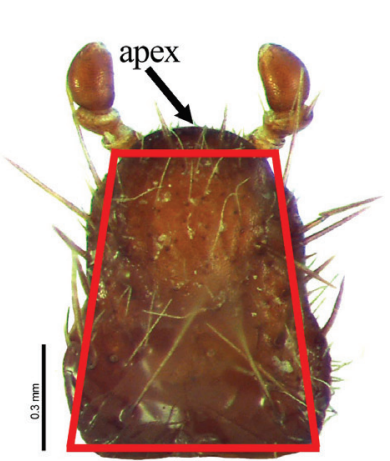

9. P. intermedius

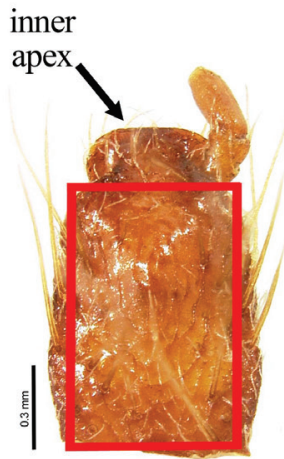

10. P. richterianus

Figures 4-10. Characters for species of Pseudogeniates 4 Left mandible of $P$. richterianus, dorsal view (with one apical, acute, recurved tooth; poorly developed scissorial region, and narrow molar region) $\mathbf{5}$ Maxilla of $P$. cordobaensis, ventral view (lacking teeth, terminal segment of palpus with dorsal, longitudinal sulcus) 6 Spiculum gastrale of $P$. cordobaensis 7 Wing of $P$. richterianus showing form and inset showing dense, thick setae associated with ScA and region anterior to RA3+4 8 Mentum, ventral view, of $P$. cordobaensis (shape pentagonal, inner apex projecting anteriorly and with inner shelf) 9 Mentum, ventral view, of $P$. intermedius (shape broadly trapezoidal, apex not projecting anteriorly and without inner shelf) I0 Mentum, ventral view, of $P$. richterianus (shape rectangular, inner apex projecting anteriorly and without inner shelf) 
Composition and distribution. The genus Pseudogeniates is composed of three species that are distributed entirely in Argentina (Fig. 22). Species are associated with arid areas of the Pampa, Espinal, Chaco, and Monte eco-regions in Argentina.

Biology. Very little is known of the biology of the species in the genus. Males and females are attracted to lights at night. Based on the extreme wear on the protibia of some specimens, individuals probably are associated with soil and use their front appendages for digging.

Etymology. The name Pseudogeniates ("the false Geniates") refers to the similarity in form to some species in the ruteline genus Geniates.

\section{Key to species of Pseudogeniates}

(Males: Protarsus with inner claw enlarged [Fig. 11]; abdomen ventrally flat or concave. Females: Protarsus with inner claw not enlarged, similar in size to outer claw [Figs $12-13$ ]; abdomen ventrally swollen or weakly convex.)

1 Mentum longer than wide, form subtrapezoidal or rectangular (Figs 9-10)...2

- $\quad$ Mentum with length subequal to width, form pentagonal (Fig. 8)

P. cordobaensis Soula

2 Mentum with inner apex not projecting anteriorly (Fig. 9), with inner shelf; female metacoxal corner square; ventral plate of male parameres nearly as long as the dorsal plate (Fig. 20)

P. intermedius Ohaus

- $\quad$ Mentum with inner apex projecting anteriorly (Fig. 10), without inner shelf; female metacoxal corner rounded; ventral plate of male parameres about half the length of the dorsal plate (Fig. 21)

P. richterianus Ohaus

\section{Pseudogeniates cordobaensis Soula, 2009}

http://species-id.net/wiki/Pseudogeniates_cordobaensis

Figs $1,5,6,8,11,14,16,19,22$

P. cordobaensis Soula 2009: 122 .

Material examined. Holotype male, from Ohaus's type series of $P$. intermedius, at ZMHB labeled: a) "Argentina S. d. Cordoba J. Hubrich S." (typeset, white label), b) male symbol, c) "Pseudogeniates intermedius cotype Ohs." (Ohaus's handwritten, red label), d) "SYNTYPUS Pseudogeniates intermedius Ohaus, 1914 labelled by MNHUS 2007" (typeset, red label), f) "Paralectotype 2009 Pseudogeniates intermedius Oh. Soula det." (typeset and handwritten, red label), g) "Holotype 2009 Pseudogeniates cordobaensis Soula Soula" (handwritten and typeset, red label). Soula (2009) based the description on one male specimen.

Description (based on 10 males and 17 females). Length 13.8-17.0 mm. Widest width 6.8-8.0 mm. Color: Dorsum, venter, and appendages rufous-castaneous (Fig. 1). 

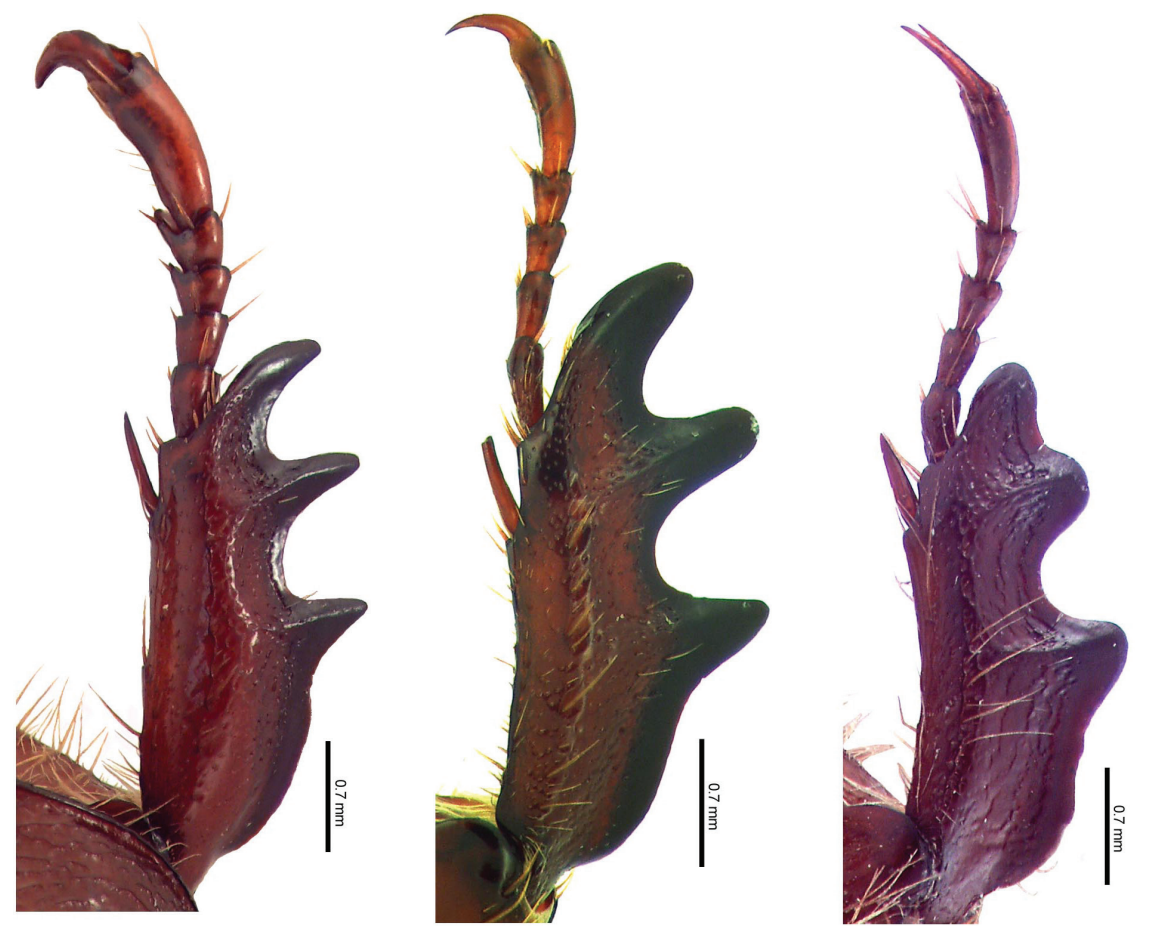

11. P. cordobaensis, 12. P. richterianus, 13. P. richterianus, male unworn female worn female
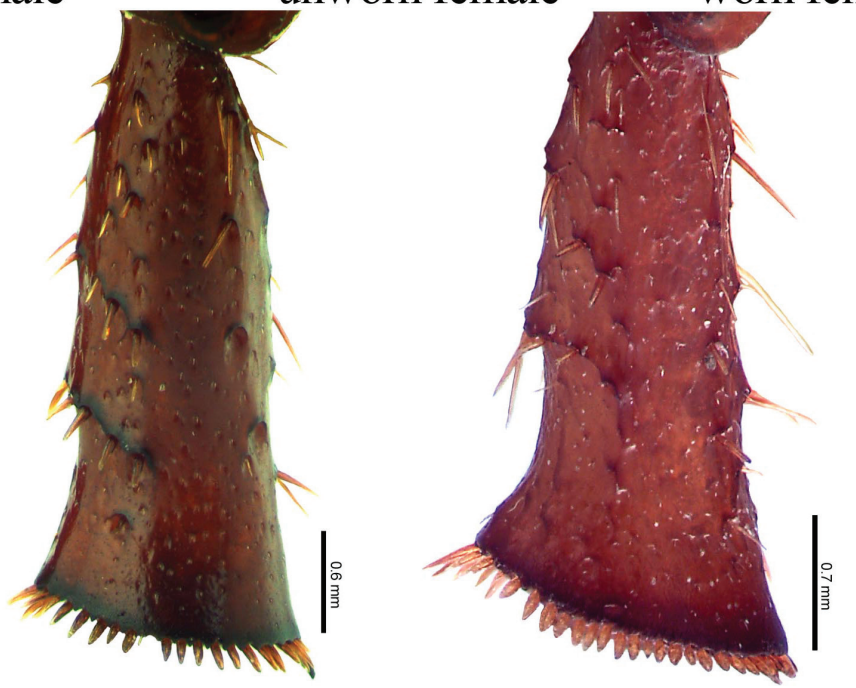

14. P. cordobaensis, male

15. P. richterianus, female

Figures II-I5. Form of protibia (11-13) and metatibia (14-15) in Pseudogeniates species II Protibia of $P$. cordobaensis (male) I $\mathbf{2}$ Protibia of unworn specimen of $P$. richterianus (female) showing $\mathbf{3}$ Protibia of worn specimen of $P$. richterianus (female) 14 Metatibia of $P$. cordobaensis (male) I5 Metatibia of $P$. richterianus (female) 
Head (Fig. 16): Frons densely punctate to confluently punctate (mid-disc), rugopunctate laterally and apically; punctures small and moderately large, mixed. Clypeus with dorsal surface densely punctate to confluently punctate (mid-disc), rugopunctate laterally and apically, punctures small and large (mixed), some setose; setae short to moderate, rufous, sparse; shape broadly semicircular, apex and sides broadly reflexed, with or without constriction basolaterally; disc (frontal view) densely rugopunctate, punctures small and large, mixed, some setose (setae short to moderately long, rufous, sparse). Labrum setose; setae moderately long and short, rufous. Maxilla (Fig. 5) with galea distinct, with 1 elongate, bristle-like, medial seta. Mentum (Fig. 8) nearly as long as wide or slightly longer than wide, form pentagonal, inner apex projects anteriorly, with inner shelf. Antenna 10-segmented with 3 segmented club; club slightly longer than stem. Pronotum: Medial line obsolete. Surface (disc and mediolaterally) moderately densely imbricate with sparse, short, testaceous setae. Margin with short, rufous setae. Elytra: Sutural stria impressed from base of scutellum to apex. Elytral apex weakly spiniform or quadrate. Discal striae weakly impressed, punctate; 5 on disc mesad of humerus, 5 laterad of humerus; discal stria 1 (adjacent to sutural stria) extending from base to apical umbone; striae 2-3 and 4-5 paired, extending from near base to apical umbone, stria 5 faintly impressed and incomplete; humeral striae 1-4 faintly impressed, incomplete, indicated by shallow punctures, stria 5 moderately impressed, extending from base of metacoxa to subapex; small to moderate in size, some longitudinal (Fig. 5). Intervals with moderately dense, random punctures, punctures minute to moderate in size; interval 1 broader than others. Pygidium: Disc and apex sparsely punctate; base and sides moderately densely imbricate, nearly obsolete; punctures minute to small. Legs: Protarsomere 5 of male subequal to tarsomeres 2-4. Modified proclaw of male subequal in length to tarsomeres 2-4; internoapical tooth present. Protibia (Fig. 11) (male and female) with teeth evenly separated; basal $1 / 3$ weakly dilated (male) or moderately dilated (female). Mesotibia (male) with sides subparallel, weakly divergent towards apex (male) or weakly divergent (female); apex oblique with 10-11 moderately long spinulae; external edge with weak carina in basal 1/3, 1 carina in apical 1/3. Metatrochanter (male) weakly produced beyond posterior border of femur. Metacoxal corner square (female). Metacoxa at middle weakly produced posteriorly. Metatibia of male (Fig. 14) with sides subparallel, weakly divergent towards apex; external edge with 1 carina in basal 1/3 (faint), 1 carina in apical 1/3 (faint); apex without corbel, with 2 inner spurs (spurs equal in width in male, weakly curved at apex), inner apex with 28 short, stout spinulae. Metatibia of female divergent at apical 1/5; external edge with 1 carina in basal 1/3, 1 carina in apical 1/3; apex without corbel, with 2 inner spurs, inner apex with 28 short, stout spinulae. Parameres: Ventral plate nearly as long as dorsal plate with sides converging to a quadrate apex (Fig. 19).

Diagnosis. Pseudogeniates cordobaensis is separated from other species in the genus by the pentagonal form of the mentum (width subequal to length) that has the inner apex projecting anteriorly and has an inner shelf (Fig. 8). In comparison, the form of mentum is longer than wide in $P$. intermedius and P. richterianus (Figs 9-10). In $P$. intermedius, the inner apex of the mentum does not project anteriorly, but does possess 


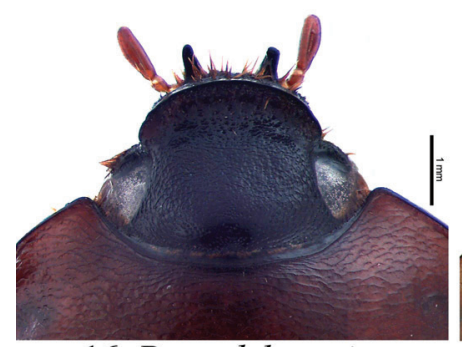

16. P. cordobaensis

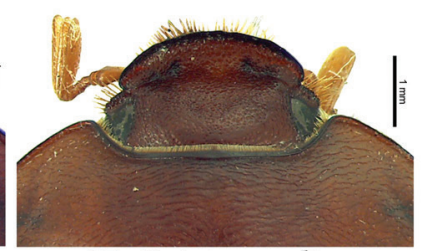

17. P. intermedius

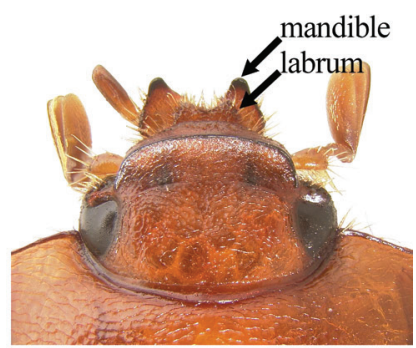

18. P. richterianus

Figures 16-18. Form of the head (dorsal view) in Pseudogeniates species 16 P. cordoboaensis showing form of clypeal apex $\mathbf{1 7} P$. intermedius showing form of clypeal apex $\mathbf{1 8} P$. richterianus showing form of clypeal apex, labrum, and mandible

an inner shelf (Fig. 9); in P. richterianus, the inner apex projects anteriorly, but does not possess an inner shelf (Fig. 10). The ventral plate of the male parameres in P. cordobaensis is nearly as long as dorsal plate with sides converging to a quadrate apex (Fig. 19). The ventral plate of $P$. richterianus is about half the length of the dorsal plate (Fig. 21), whereas in P. intermedius the ventral plate is nearly as long as the dorsal plate, but the sides converge with a weak constriction preapically and a rounded apex (Fig. 20).

Distribution (Fig. 22). Pseudogeniates cordobaensis is distributed in the Monte de Sierras y Bolsones in the Monte eco-region in Argentina. The distribution of this species coincides with the Montane Forest region (Navarro et al. 2009) and the Yungas Forest area of endemism in Argentina (Szumik et al. 2012).

Locality data. 27 specimens from IAZA, WSUC, and ZMHB. ARGENTINA (27): CATAMARCA (26): Salar de Pipanaco, Pío Brizuela (37 km S Andalgalá, 2749'34"S,

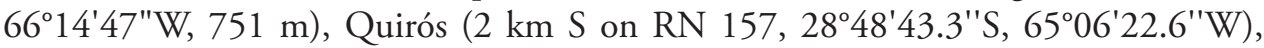
CÓRDOBA (1): Huerta Grande (Sierra de Córdoba).

Temporal data. December (9).

Remarks. The holotype specimen for this species was part of the type series for $P$. intermedius, a series that included three specimens from Santiago del Estero and one specimen (=P. cordobaensis) from Huerta Grande in the Sierra de Cordóba, Córdoba Province (Ohaus 1914).

Natural history. This species is attracted to black lights. It was recorded from an elevation of $751 \mathrm{~m}$.

\section{Pseudogeniates intermedius Ohaus, 1914}

http://species-id.net/wiki/Pseudogeniates_intermedius

Figs 2, 9, 17, 20

P. intermedius Ohaus 1914: 303.

Material examined. Type material (3 males, 1 female) at ZMHB. Lectotype male labeled: a) "ARGENTINA Santiago d E. Wagner" (typeset, white label), b) male genitalia 
card-mounted, c) mouthparts card-mounted, d) "Typus!" (typeset, red label), e) "Pseudogeniates intermedius Ohs." (Ohaus' handwritten, red label), f) "SYNTYPUS Pseudogeniates intermedius Ohaus, 1914 labelled by MNHUS 2007" (typeset, red label), g) "Lectotype 2009 Pseudogeniates intermedius Oh. Soula" (typeset and handwritten, red label). Paralectotype female labeled: a) "ARGENTINA Santiago del Estero" (typeset, white label), b) female symbol, c) mouthparts card-mounted, d) "Pseudogeniates intermedius cotype Ohs." (Ohaus' handwritten, red label), e) "SYNTYPUS Pseudogeniates intermedius Ohaus, 1914 labelled by MNHUS 2007” (typeset, red label), f) "Paralectotype 2009 Pseudogeniates intermedius Oh. Soula det." (typeset and handwritten, red label), g) "Alloréférent Pseudogeniates intermedius M. SOULA det 19" (handwritten and typeset, white label with scribed red boarder), h) "Paralectotype 2009 Pseudogeniates intermedius Oh. Soula det." (typeset and handwritten, red label). A second male paralectotype labeled: a) "MUSEUM PARIS PROV. DE SANTIAGO del Estero Barrancas Banados de Rio Dulce, 80 kil. O. d'Icano E.R. WAGNER 1909”, b) "Pseudogeniates intermedius cotype Ohs." (Ohaus' handwritten, red label), c) "SYNTYPUS Pseudogeniates intermedius Ohaus, 1914 labelled by MNHUS 2007” (typeset, red label), d) "Paralectotype 2009 Pseudogeniates intermedius Oh. Soula det." (typeset and handwritten, red label). An additional paralectotype from Córdoba is the holotype specimen for $P$. cordobaensis Soula (see treatment for P. cordobaensis). Ohaus (1914) stated that he described the species based on four specimens: two males and one female from Santiago del Estero (Wagner collection) and one male from Sierra de Córdoba.

Description (based on 2 males and 1 female). Length 14.0-15.7 mm. Widest width 7.5-9.0 mm. Color: Dorsum, venter, and appendages rufotestaceous to castaneous (Fig. 2). Head (Fig. 17): Frons densely, confluently punctate or rugopunctate; punctures small and moderately large, mixed. Clypeus with dorsal surface densely punctate, confluently punctate or rugopunctate, punctures small and large, mixed; clypeal shape broadly semicircular, apex and sides broadly reflexed, with or without constriction basolaterally; disc (frontal view) with surface densely rugopunctate, punctures small and large, mixed, some setose (setae short to moderately long, rufous, sparse). Labrum with setae moderately long and short, rufous. Maxilla with galea fused, with 1 or 2 elongate bristle-like, medial, setae. Mentum (Fig. 9) longer than wide, form subtrapezoidal (base broader than apex), inner apex not projecting anteriorly, with inner shelf. Antenna 10-segmented with 3 segmented club; club subequal to stem. Pronotum: Medial line obsolete (male) or weakly indicated (female). Surface (disc) moderately densely imbricate with sparse, short, testaceous setae; surface (mediolaterally) moderately densely rugopunctate, punctures minute and small. Margin with setae short, testaceous. Elytra: Elytral apex rounded or quadrate (not spiniform). Discal striae punctate; 5 on disc mesad of humerus, 5 laterad of humerus; discal stria 1 (adjacent to sutural stria) extending from base to apical umbone; striae 2-3 and 4-5 paired, extending from near base to apical umbone; humeral stria 1 incomplete (extending from mid-elytron to near apical umbone), stria 2 extending from humerus to near apical umbone, striae 3-4 extending from base of metacoxa to near apical umbone (indicated by punctures, not sulcate), stria 5 poorly indicated, extending from 


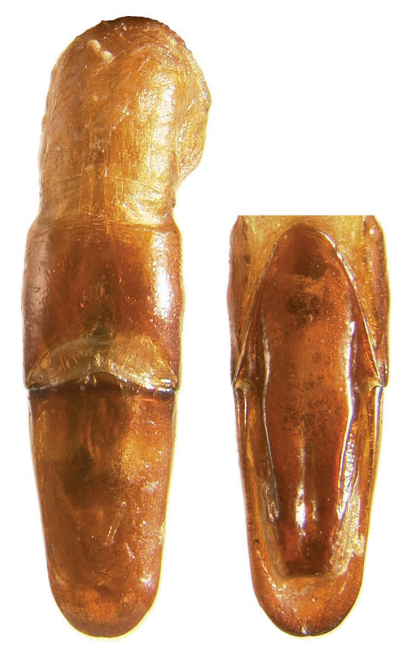

\section{P. cordobaensis}

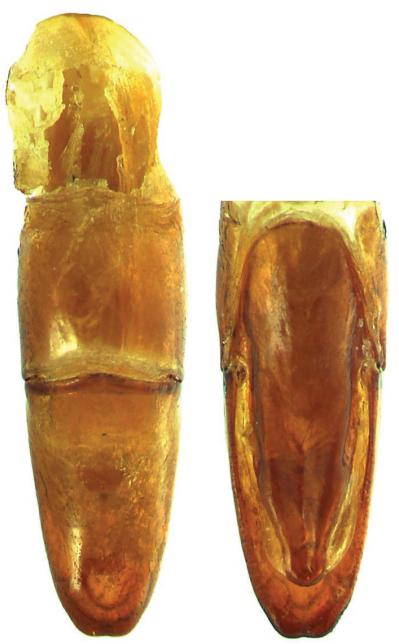

20. P. intermedius

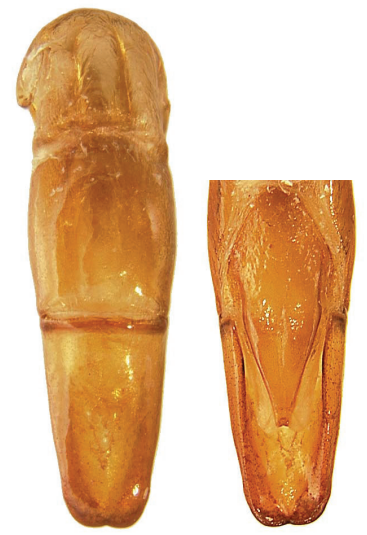

21. P. richterianus

Figures 19-2 I. Form of male parameres (dorsal and ventral views) in Pseudogeniates species 19 P. cordobaensis (ventral plate nearly as long as dorsal plate, apex quadrate) $\mathbf{2 0}$ P. intermedius (ventral plate nearly as long as dorsal plate, apex rounded) $\mathbf{2} \mathbf{I}$ P. richterianus (ventral plate about half length of dorsal plate, apex acute)

base of metacoxa to subapex (indicated by punctures near base, sulcate near apex); punctures small, some longitudinal. Intervals with moderately dense, random punctures, some transversely wrinkled (on disc), punctures small; interval 1 broader than others. Pygidium: Disc and apex moderately densely punctate, some transverse; base and sides closely, weakly rugulose; punctures minute to small. Legs: Protarsomere 5 of male subequal to tarsomeres 2-4. Modified foreclaw of male subequal in length to tarsomeres 2-4; internoapical tooth present. Protibia (male and female) with external teeth evenly separated; basal $1 / 3$ weakly dilated (male) or moderately dilated (female) (e.g., Figs 11-13). Mesotibia (male) with sides subparallel, weakly divergent towards apex; apex oblique with 8-11 moderately long spinulae; external edge with weak carina in basal 1/3,1 carina in apical 1/3. Metatrochanter (male and female) weakly produced beyond posterior border of femur. Metacoxal corner square (female). Metacoxa at middle weakly produced posteriorly. Metatibia (male) with sides subparallel, apex weakly divergent; external edge with 1 carina in basal $1 / 3,1$ carina in apical 1/3; apex without corbel, with 2 inner spurs (spurs equal in width in male, with a weak curve at apex), inner apex with 21-25 short, stout spinulae. Metatibia (female) greatly divergent at apical 1/5; external edge with 1 carina in basal $1 / 3,1$ carina in apical 1/3; apex without corbel, with 2 inner spurs, inner apex with 28 short, stout spinulae. Parameres: Ventral plate nearly as long as dorsal plate but the sides converge with a weak constriction preapically and a rounded apex (Fig. 20).

Diagnosis. Pseudogeniates intermedius is known from only three specimens. It is separated from other species in the genus by the form of the mentum (Fig. 9) and the form of the male parameres (Fig. 20). It is distinguished from P. cordobaensis by the form of the mentum (longer than wide and subtrapezoidal in P. intermedius [Fig. 9]; length 
subequal to width and pentagonal in P. cordobaensis [Fig. 8]) and apex of the ventral plate of the male parameres (with a weak constriction preapically and a rounded apex in $P$. intermedius [Fig. 20]; lacking preapical constriction and with quadrate apex in $P$. cordobaensis [Fig. 19]). It is separated from P. richterianus by the apex of the mentum (with an inner shelf in $P$. intermedius; lacking inner shelf in P. richterianus [Fig. 9 versus Fig. 10]) and length of the ventral plate of the male parameres (nearly as long as dorsal plate in P. intermedius [Fig. 20]; half length of dorsal plate in P. richterianus [Fig. 21]).

Distribution (Fig. 22). Pseudogeniates intermedius is distributed in the Chaco-seco eco-region in Argentina.

Locality data. 3 specimens from ZMHB. ARGENTINA (3): SANTIAGO DEL ESTERO (3): Barrancas (Bañados de Río Dulce, $80 \mathrm{~km} \mathrm{W.} \mathrm{d’Icaño),} \mathrm{No} \mathrm{data.}$

Temporal data. December (1).

Natural history. This species is known from two male specimens and one female specimen, and the natural history is not known.

Remarks. Ohaus (1914) distinguished P. intermedius from P. richterianus based on the 10-segmented antenna (versus 9-segmented in $P$. richterianus), the "front corners" of the clypeus (rounded in $P$. richterianus versus absent in $P$. intermedius), and elytral coloration (brownish-red color in $P$. intermedius versus reddish-yellow in $P$. richterianus). Based on our examination of specimens, these characters are highly variable and are not reliable for identification. Coloration varies within species (from testaceous to castaneous), form of the clypeus varies, and antennae vary from 9 to 10 segments. However, characters provided in our "Diagnosis" are sufficient to separate P. intermedius and $P$. richterianus.

\section{Pseudogeniates richterianus Ohaus, 1910}

http://species-id.net/wiki/Pseudogeniates_richterianus

Figs 3-4, 7, 10, 12-13, 15, 18, 21-22

P. richterianus Ohaus 1910: 180.

P. richteri Ohaus (lapsus in Ohaus 1934, table 2, figure 6).

Material examined. Two female co-types examined at ZMHB. Female lectotype labeled: a) "ARGENTINA Buenos Aires XII.08 H.R." (typeset and handwritten on upperside and underside of white label), b) "Pseudogeniates Richteri cotype Ohs." (Ohaus' handwritten, red label), c) "SYNTYPUS Pseudogeniates richterianus Ohaus, 1910 labelled by MNHUB 2007” (typeset, red label), d) “Lectotype 2009 Pseudogeniates Richterianus Oh. Soula” (typeset and handwritten, red label). Paralectotype female labeled: a) "Rep. Argentina Prov. Santa Fe, R. Richter", b) female symbol, c) mouthparts card-mounted, d) “Typus!” (typeset, red label), e) "Pseudogeniates Richterianus Oh." (Ohaus' handwritten, red label), f) "SYNTYPUS Pseudogeniates richterianus Ohaus, 1910 labelled by MNHUB 2007" (typeset, red label), d) "Lectotype 2009 Pseudogeniates Richterianus Oh. Soula det." (typeset and handwritten, red label). The 


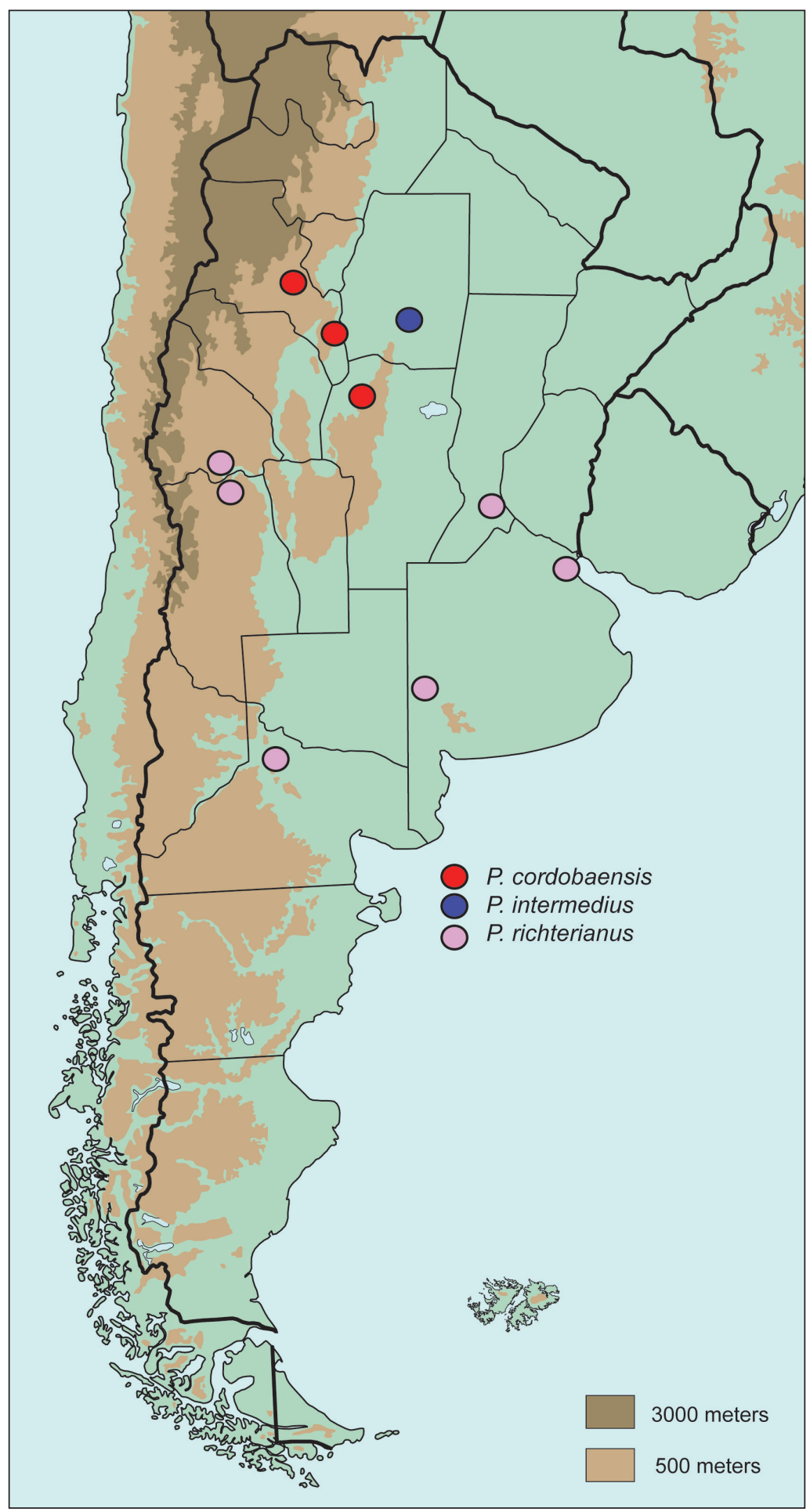

Figure 22. Distribution of Pseudogeniates species in Argentina 
paralectotype has the head, thorax, and abdomen glued together. It is, in fact, a chimera with the head of Parhomonyx fuscoaneus and body of Pseudogeniates richterianus. Ohaus (1910) stated that he described the species based on three female specimens from Santa Fé, Argentina (Hans Richter collection) and Buenos Aires. The location of one specimen is not known.

Description (based on 4 males and 22 females). Length 12.0-18.4 mm. Widest width 7.8-10.0 mm. Color: Dorsum, venter, and appendages rufotestaceous to castaneous (Fig. 3). Head (Fig. 18): Frons moderately densely punctate or rugopunctate; punctures small and moderately large, mixed. Clypeus with dorsal surface weakly rugopunctate, punctures small and large, mixed; shape broadly rounded apically and laterally or subquadrate, with or without constriction basolaterally, apex and sides broadly reflexed; disc (frontal view) moderately densely punctate or rugopunctate, punctures small and large, mixed, some setose (setae short, testaceous, sparse). Labrum with setae moderately long and short, testaceous. Maxilla with galea not fused, with 1-2 moderately long, bristle-like medial setae. Mentum (Fig. 10) longer than wide, rectangular, inner apex projecting anteriorly, without inner shelf. Antenna 9 or 10-segmented with 3-segmented club; club subequal to or slightly longer than stem. Pronotum: Medial line weakly impressed or obsolete. Surface (disc) moderately densely punctate (mid-disc), rugopunctate, or imbricate; punctures small to moderate. Margin with setae moderately long, testaceous. Elytra: Elytral apex rounded, quadrate, or with obtuse angle. Discal stiae, sulcate-punctate; 5 on disc mesad of humerus, 5 laterad of humerus; discal stria 1 (adjacent to sutural stria) extending from base to apex, stiae 2-6 extending from near base to apical umbone; humeral stria 1 incomplete (extending from mid-elytron to near apical umbone), stria 2 extending from humerus to near apical umbone, striae 3-4 extending from base of metacoxa to near apical umbone (indicated by punctures, not sulcate), stria 5 extending from base of metacoxa to subapex (indicated by punctures near base, sulcate near apex); punctures small to moderate in size, some longitudinal. Intervals with moderately dense, random punctures, some transversely wrinkled (on disc), punctures small to moderate in size; interval 1 subequal in width to other intervals. Pygidium: Disc and apex moderately densely punctate or transversely rugopunctate; base and sides closely, rugopunctate or weakly rugose; punctures small. Legs: Protarsomere 5 of male slightly longer than tarsomeres 2-4. Modified foreclaw of male slightly longer than tarsomeres 2-4; internoapical tooth present. Protibia with external teeth often worn; 2 apical teeth removed from basal tooth; basal 1/3 weakly dilated (male; Fig. 12) or moderately dilated (female; Fig. 13). Mesotibia with sides subparallel, apex weakly divergent and weakly oblique; external edge with weak carina in basal $1 / 3$, 1 carina in apical 1/3; apex with 8-14 short spinulae. Metatrochanter weakly produced beyond posterior border of femur. Metacoxal corner (female) rounded, with or without inner tooth. Metacoxa at middle not produced posteriorly. Metatibia (male) with sides subparallel, apex moderately divergent in apical $1 / 3$; external edge with 1 carina in basal $1 / 4,1$ carina in apical 1/4; apex without corbel, with 2 inner spurs (spurs equal in width in male), inner apex with 28-35 short, stout spinulae. Metatibia (female; Fig. 15) greatly divergent at apical 1/4; external edge with 1 carina in basal 1/3, 1 carina in apical 1/3; 
apex without corbel, with 2 inner spurs, inner apex with 28-35 short, stout spinulae. Parameres: Ventral plate half length of dorsal plate (Fig. 21).

Diagnosis. Pseudogeniates richterianus is a highly variable species. Variation is observed in the antenna (9- or 10-segmented), labrum (weakly or moderately emarginated), length of antennal club (subequal to slightly longer then the stem), elytral apex (spiniform, quadrate, rounded, or obtusely angled), pronotal medial line (weak or obsolete), and form of the clypeus. However, several characters reliably separate this species from others in the genus. Pseudogeniates richterianus is separated from $P$. intermedius and $P$. cordobaensis by the form of the mentum (rectangular and without inner shelf in $P$. richterianus [Fig. 10]; subtrapezoidal and with inner shelf in $P$. intermedius [Fig. 9]; pentagonal and nearly as wide as long in P. cordobaensis [Fig. 8]), ventral plate of the parameres (half length of the dorsal plate in $P$. richterianus [Fig. 21]; nearly as long as dorsal plate in P. intermedius and P. cordobaensis [Figs 20 and 19, respectively]), metacoxal corner in female (rounded in $P$. richterianus; square in $P$. intermedius and in $P$ cordobaensis), and posterior margin of the metacoxa (not produced posteriorly in $P$. richterianus; produced posteriorly in $P$. intermedius and $P$. cordobaensis).

Distribution (Fig. 22). Pseudogeniates richterianus is the most wide-spread species in the genus. It is distributed in the Pampa, Espinal, and Monte de Llanuras y Mesetas (Monte) eco-regions in Argentina.

Locality data. 26 specimens deposited in CMNC, FMNH, IAZA, MACN, MLJC, UCCC, and ZMHB. ARGENTINA (26): BUENOS AIRES (16): Caballito, Dept. Puán, No data. MENDOZA (7): Lavalle (Brazo S. Río San Juan Area San Miguel S 32²0'7", W 68²6'57.9", 500 m), San Rafael, No data. NEUQUEN (1): No data. RIO NEGRO (1): Villa Regina. SAN JUAN (1): Los Berros (Dept. Sarmiento). SANTA FE (1): Rosario.

Temporal data. November (5), January (3), February (1).

Natural history. Based on specimens in collections, there is a female sex bias in this species (24 females: 4 males). Many specimens (male and female) have worn protibiae (Fig. 13), indicating that adults dig in abrasive soil. Label data indicate that this species was collected at mercury vapor light and at $500 \mathrm{~m}$ elevation.

Remarks. Ohaus (1914) distinguished P. richterianus from P. intermedius based characters that vary within the species (see "Remarks" for P. intermedius), including number of antennal segments, form of the clypeus, and coloration. Although these characters are unreliable for diagnosis of the species, we provide characters that are useful (see "Diagnosis"). Ohaus (1910) named the species in honor of Herr Hans Richter from Buenos Aires.

\section{Discussion}

Species in the genus Pseudogeniates exhibit a great deal of character variation, thus causing historical difficulty with circumscription of the species. Variation in the number of antennomeres, length of the antennal club, and form of the clypeal apex, 
labrum, elytral apex exhibit intraspecific variability. Variation of this degree is not unprecedented within the Scarabaeoidea. In particular, species associated with high elevations (e.g., Parabyrsopolis Ohaus) and species associated with arid habitats (e.g., Anomiopsoides heteroclyta (Blanchard), Eucranium arachnoides Brullé [both Scarabaeinae], and Allidiostoma hirtum Ohaus [Allidiostomatinae]) are known to possess broad intraspecific variation (Jameson 1990, Ocampo 2007). In some populations, individuals of Parabyrsopolis chibuahuae (Bates) exhibit a wide range in clypeal shapes (quadrate or parabolic, reflexed or not) (Jameson 1990). Individuals of A. heteroclyta exhibit high variability in clypeal shapes and clypeal processes, as well as variation in pronotal sculpture (puncture shape and density) (Ocampo 2007). Species in the Mexican genus Parachrysina Bates are unusual in that some species have 8-segmented antennae and others have 9-segmented antennae (Jameson 1991). Molecular analysis of species of Pseudogeniates, as well as other highly variable species, may reveal underlying mechanisms for high intraspecific variation.

High intraspecific variation may have been the product of historical climatic and concomitant habitat fluctuations. During the Pleistocene, climatic fluctuations in northern Argentina may have resulted in broad regions being inhabited by Yungas forests (reaching to Córdoba province in the south) (Navarro et al. 2009). Subsequently, these forests have been replaced with remnant patches of Yungas, Chaco, and Espinal forests (Navarro et al. 2009). Climatic fluctuations and changing habitats, in combination with the latitudinal and altitudinal gradient of the montane region (Barquez and Díaz 2001), may have assisted in isolating populations (such as ancestral populations of Pseudogeniates), influencing species diversifications, and leading to high levels of endemism (Navarro et al. 2009, Szumik et al. 2012).

\section{Acknowledgments}

We thank the curators, collections managers, and individuals listed in the "Taxonomic Materials" section for their loan of specimens and for their assistance. We thank Adriana Marvaldi and Jose Mondaca for their thoughtful reviews and valuable suggestions. Partial support for completion of this research was provided by CONICET (Consejo Nacional de Investigaciones Científicas y Técnicas, Argentina) through the following grant: PIP \#112-200801-01869 and by ANPCyT (Agencia Nacional de Promoción Científica y Técnica, Argentina) PICT-2011-2573. FCO thanks CONICET (Argentina) and the Instituto de Ciencias Básicas, Universidad Nacional de Cuyo for continued research support.

\section{References}

Barquez RM, Díaz MM (2001) Bats of the argentine Yungas: A systematic and distributional analysis. Acta Zoologica Mexicana 82: 29-81. 
Cabrera AL, Willink A (1973) Biogeografía de América Latina. Monografía 13, Serie de Biología OEA, Washington, DC.

Jameson ML (1998) [1997] Phylogenetic analysis of the subtribe Rutelina and revision of the Rutela generic groups (Coleoptera: Scarabaeidae: Rutelinae: Rutelini). Bulletin of the University of Nebraska State Museum 14: 1-184.

Jameson ML (1990) Revision, phylogeny and biogeography of the genera Parabyrsopolis Ohaus and Viridimicus (new genus) (Coleoptera: Scarabaeidae: Rutelinae). The Coleopterists Bulletin 44: 377-422.

Jameson ML (1991) A new species of Parachryina (Coleoptera: Scarabaeidae: Rutelinae) from Nuevo Leon, Mexico. The Coleopterists Bulletin 45(1): 232-238.

Jameson ML (2005) Key to Tribes of Rutelinae (Scarabaeidae). www.museum.unl.edu/research/entomology/Guide/Rutelinae/RutelinaeK.htm [accessed July 2012]

Jameson ML, Hawkins SJ (2005) Synopsis of the genera of Geniatini (Coleoptera: Scarabaeidae: Rutelinae) with an annotated catalog of species. Zootaxa 874: 1-76.

Machatschke J (1965) Coleoptera Lamelicornia. Fam. Scarabaeidae, Subfam. Rutelinae, Section Rutelinae Orthochilidae. Genera Insectorum, Fasc. 199C, 1-145.

Navarro FR, Cuezzo F, Goloboff PA, Szumik C, Lizarralde de Grosso M, Quintana MG (2009) Can insect data be used to infer areas of endemism? An example from the Yungas of Argentina. Revista Chilena de Historia Natural 82: 507-522. doi: 10.4067/S0716078X2009000400006

Ocampo FC (2007) Description of a new species of Anomiopsoides, with proposal of new synonyms for Anomiopsoides heteroclyta (Scarabeidae: Scarabeinae: Eucraniini). Revista de la Sociedad Entomológica Argentina 66: 159-168.

Ohaus F (1910) Neue Coleoptera lamellicornia aus Argentinien. Deutsche Entomologische Zeitschrift 1910: 173-186.

Ohaus F (1914) Neue Coleoptera lamellicornia aus Argentinien. (Col.) IV. Deutsche Entomologische Zeitschrift 1914: 299-304. doi: 10.1002/mmnd.191419140307

Ohaus F (1915) XVI. Beitrag zur Kenntnis der Ruteliden. (Col. Lamell.). Deutsche Entomologische Zeitschrift 1915: 256-260. doi: 10.1002/mmnd.191519150308

Ohaus F (1918) Scarabaeidae: Euchirinae, Phaenomerinae, Rutelinae. Coleopterum Catalogus 20: $1-241$.

Ohaus F (1934) Coleoptera Lamellicornia. Fam. Scarabaeidae, Subfam. Rutelinae. Genera Insectorum Fasc. 1999A: 1-172.

Ponce M, Mehltreter K, R de la Sota E (2002) Análisis biogeográfico de la diversidad pteridofítica en Argentina y Chile continental. Revista Chilena de Historia Natural 75: 703-717. doi: 10.4067/S0716-078X2002000400006

Soula M (2009) Les coleopteres du nouveau monde. Volume 3: Rutelini 3. Révision des Pelidnotina 3. Photos de toutes le espéces de Lagochile. Une révision des genres Pelidnota, Ectinoplectron, Pseudogeniates, Xenopelidnota (Coleoptera: Scarabaeidae: Rutelinae: Rutelini: Pelidnotina). Besoiro: Supplément au Bulletin de liaison de l'Association Entomologique pour la Connaissance de la Faune Tropicale. AECFT; Saintry, France, 137 pp.

Szumik C, Aagesen L, Casagranda D, Arzamendia V, Baldo D, Claps LE, Cuezzo F, Gómez JMD, Di Giacomo A, Giraudo A, Goloboff P, Gramajo C, Kopuchian C, Kretzschmar S, 
Lizarralde M, Molina A, Mollerach M, Navarro F, Nomdedeu S, Panizza A, Pereyra VV, Sandoval M, Scrocchi G, Zuloaga FO (2012) Detecting areas of endemism with a taxonomically diverse data set: plants, mammals, reptiles, amphibians, birds, and insects from Argentina. Cladistics 28: 317-329. doi: 10.1111/j.1096-0031.2011.00385.x

Wheeler QD, Platnick NI (2000) The phylogenetic species concept (sensu Wheeler and Platnick. In: Wheeler QD, Meier R (Eds) Species Concepts and Phylogenetic Theory. A Debate. Columbia University Press, New York, 55-69.

\section{Appendix}

Pseudogeniates locality table. (doi: 10.3897/zookeys.241.3802.app) File format: Microsoft Excel document (xls).

Explanation note: Distribution maps were generated by entering latitude and longitude data into Microsoft Excel 2008 and uploaded to EarthPoint (http://www.earthpoint.us/ExcelToKml.aspx) and GoogleEarth (http://www.google.com/earth/index. html). This supplementary file allows addition of data and interactive mapping or niche modeling.

Copyright notice: This dataset is made available under the Open Database License (http://opendatacommons.org/licenses/odbl/1.0/). The Open Database License $(\mathrm{ODbL})$ is a license agreement intended to allow users to freely share, modify, and use this Dataset while maintaining this same freedom for others, provided that the original source and author(s) are credited.

Citation: Jameson ML, Ocampo F (2012) Synopsis of the Argentinian scarab genus Pseudogeniates Ohaus (Coleoptera, Scarabaeidae, Rutelinae). ZooKeys 241: 33-35. doi: 10.3897/zookeys.241.3802.app 